\title{
Lenguaje y derecho: cuando la filosofía del derecho no es suficiente
}

\author{
Language and Law: When the Philosophy \\ of Law is not Sufficient
}

Ismael Martínez*

Recepción:14/6/2017

Evaluación: 23/8/2017

Aceptación final: 11/12/2017

Resumen: Este artículo es un comentario sobre el libro El Lenguaje del Derecho, de Andrei Marmor. Aquí reconstruyo las afirmaciones principales ofrecidas por Marmor en cada capítulo y los argumentos que las apoyan. Luego expreso algunas observaciones críticas dirigidas, en general, al argumento central presentado en el capítulo correspondiente. Palabras clave: Filosofía del Derecho, Lenguaje, teoría jurídica

\begin{abstract}
This article is a commentary on Andrei Marmor's book The Language of Law. Here I reconstruct the main statements offered by Marmor in each chapter and the arguments that support them. I make then some critical remarks, which are generally directed at the central argument presented in each chapter.
\end{abstract}

Keywords: Philosophy of Law, Language, legal theory

* Doctorando. Universidad de Edimburgo. 
Utilizar algunas de las herramientas que la filosofía del lenguaje ofrece para elucidar ciertos problemas al interior de la teoría jurídica es un modo de proceder conocido desde hace tiempo por los filósofos del derecho. Encontrar un esfuerzo profundo para llevar a cabo esta clase de empresa en tiempos recientes es, sin embargo, poco frecuente. E1 libro El lenguaje del derecho (The Language of Law) de Andrei Marmor ${ }^{1}$ es posiblemente el intento más serio y mejor logrado, en los últimos diez años dentro de la filosofía jurídica de tradición analítica, por llevar a cabo esta tarea. La relevancia de un trabajo de este tipo es evidente si aceptamos que el lenguaje es el instrumento primordial con el que trabaja cualquier persona involucrada en la práctica jurídica. Un libro así es de interés, principal aunque no exclusivamente, para filósofos del derecho, en particular para aquellos interesados en la interpretación, la determinación del contenido de una prescripción legal y los problemas de la verdad y la comunicación en el derecho. Por supuesto, el libro también interesa a estudiantes y a cualquier persona que desee mejorar su entendimiento sobre la relación entre lenguaje y derecho.

El propósito del libro es claro, mostrar cómo un mejor entendimiento acerca del lenguaje en general puede ser útil para mejorar nuestra comprensión sobre el funcionamiento del derecho. El objetivo de Marmor, conviene aclarar, no es utilizar la filosofía del lenguaje para ofrecer una teoría general del derecho, sino uno mucho más modesto; a saber, aprovechar los recursos que los filósofos han ofrecido en fechas recientes para comprender mejor la comunicación lingüística y aplicarlos al caso jurídico, dado que esta es el medio a través del cual se transmiten los contenidos legales. El objetivo de Marmor es tan modesto que incluso se concentra en una parte específica del discurso legal: el derecho legislado o legislativo (statutory law). En pocas palabras, el objetivo es (6) "utilizar algunos avances recientes en filosofía del lenguaje para elucidar algunos aspectos fundamentales de la comunicación legal, principalmente en el contexto del derecho legislativo".

Procederé de la siguiente manera, capítulo por capítulo, reconstruiré las afirmaciones principales ofrecidas por Marmor y los argu- 
mentos que las apoyan. Inmediatamente después, expresaré algunas observaciones críticas dirigidas, en general, al argumento central presentado en el capítulo. Desafortunadamente, la complejidad de los argumentos y la posible falta de familiaridad con la filosofía del lenguaje de un lector no experto, me obligan a reconstruir los contenidos del libro de manera particularmente extensa (aunque por supuesto no exhaustiva) en detrimento del desarrollo en detalle de mis observaciones críticas.

En el capítulo uno Marmor argumenta en favor de la tesis de que la promulgación de leyes es un acto de habla a través del cual un contenido particular es comunicado. Si esto es cierto, sostiene, la metodología apropiada para elucidar algunas de las características relevantes del derecho legislativo consiste en analizar las características del tipo de acto de habla con el cual se identifica y la manera en la que el contenido que expresa es determinado. El capítulo está dividido en dos partes; en la primera Marmor busca dar respaldo a su afirmación de que la promulgación legislativa es de hecho un acto de habla; y en la segunda, analiza la manera en la que su contenido se determina.

Según Marmor, de acuerdo con el punto de vista estándar (12), "la acción colectiva de los legisladores de promulgar una ley es un acto de habla colectivo, a través de cual algún contenido es comunicado, el cual es, esencialmente, el contenido de la ley sobre la cual se ha votado". Conviene aquí hacer explícitas las afirmaciones con las que esta tesis está comprometida: 1) que la acción de promulgar una ley es un acto colectivo; 2) que la mejor manera de entender ese acto es como un acto de habla colectivo; 3 ) que dicho acto de habla comunica un contenido específico y 4) que el contenido comunicado es el contenido legal del acto legislativo.

En general, la defensa del punto de vista estándar ofrecida por Marmor consiste en probar que las posturas escépticas, aquellas que niegan el carácter comunicativo de los actos de promulgación legislativa, son falsas. El argumento comienza con la suposición (defendida en el capítulo tres) de que, entre los distintos tipos de actos de habla, la promulgación de leyes es similar a la aserción. En particular, Marmor supone que las directivas jurídicas, al estilo de las aserciones en contextos de 
conversación ordinaria, expresan un contenido (proposicional) cuyo valor de verdad es susceptible de evaluación. Para entender el argumento, es necesario tener en mente que existe una diferencia entre el contenido expresado (asserted content) y el contenido implicado (implicated content) de la proferencia de un enunciado. Marmor advierte que su argumento se concentrará en el primero, dejando para el capítulo dos la exploración del segundo. Una aclaración más antes de comenzar la crítica al punto de vista escéptico es que el contenido expresado queda regularmente subdeterminado por la semántica y la sintaxis. En otras palabras, Marmor afirma que aunque ciertos factores semánticos y sintácticos condicionan cuál es el contenido expresado por una proferencia, este solo puede ser (en la mayoría de los casos) plenamente determinado si además atendemos a la intención (comunicativa) del hablante y a la capacidad del oyente para entenderla. Es importante tener claro que, de acuerdo con Marmor, el éxito de los actos de habla, en términos de su capacidad para comunicar un cierto contenido, está dado por el hecho de que la intención comunicativa del hablante es completamente comprendida por el oyente.

La primera objeción escéptica que el argumento enfrenta se concentra en la figura del sujeto que lleva a cabo un acto de habla. Según el escéptico, no es claro que los actos de habla puedan ser actos colectivos. No obstante, la razón para creer lo anterior, afirma Marmor, difícilmente tiene que ver con la mera atribución de acciones a grupos, pues, de hecho, atribuir la realización de actos intencionales a conjuntos de individuos es algo que hacemos con regularidad; por ejemplo, cuando hablamos de las anotaciones de un equipo en cualquier deporte de conjunto. Cabe precisar aquí que el argumento de Marmor en contra de esta posible interpretación de la tesis escéptica no parece ignorar la distinción entre la "atribución" de una acción a un agente y la "realización” de esa acción. La afirmación de Marmor es precisamente que, en ocasiones, grupos de personas llevan a cabo acciones, incluso si en sentido estricto son más bien realizadas individualmente por los miembros que los integran. Es el equipo el que "gana" un partido, y no uno (o todos individualmente) de sus jugadores. 
Lenguaje y derecho: cuando la filosofía del derecho no es suficiente

Si esto es así, el argumento escéptico tendría que señalar, para ser exitoso, una diferencia relevante entre los actos de habla y otras acciones que sin dificultad atribuimos a colectividades. Para mostrar que dicha diferencia no existe, Marmor se apoya en la ubicuidad con la que las personas utilizan el pronombre personal de la primera persona del plural "nosotros" en sus prácticas lingüísticas ordinarias, mediante las cuales atribuyen la realización de actos de habla a colectividades. Según Marmor, es común que las personas expresen enunciados como "(nosotros) te invitamos", "(nosotros) te prometemos" etc. La frecuencia con la que aparecen estas expresiones en nuestra vida diaria deja en claro que, tal y como pasa con algunas acciones intencionales, los actos de habla pueden realizarse por grupos de personas.

Incluso si lo anterior es cierto y no hay ningún problema en atribuir a un conjunto de individuos la realización de un acto de habla, el escéptico puede alegar aún que el contexto en el que toma decisiones una asamblea legislativa democrática no puede ser explicado adoptando el modelo estándar. En pocas palabras, el escéptico podría negar que los actos legislativos sean actos de habla. Los legisladores promulgan leyes a través de votaciones y no a través de las declaraciones de uno (o algunos) en representación del resto. De este modo, según Marmor, la discusión con el escéptico se reduce a la pregunta sobre si votar es o no un acto de habla. El escéptico, claramente, responde a esta pregunta negativamente. Votar no es un acto de habla porque, al emitir su voto, cada legislador podría intentar comunicar un mensaje completamente distinto al que intentan comunicar sus compañeros. No obstante, afirma Marmor, una cosa es clara(18): "cuando los legisladores votan para aprobar una resolución particular, expresan la intención de comunicar el contenido de la resolución como la decisión oficial de la institución en cuestión". El argumento más sofisticado que puede presentar el escéptico se concentra en la inexistencia de algo que pueda considerarse el contenido asertivo de un acto legislativo. La razón para sostener lo anterior es que, de acuerdo con el escéptico, el contenido asertivo de la proferencia de una oración está determinado exclusivamente por las intenciones del hablante. Dado que en el contexto legislativo es sumamente difícil identificar a la(s) persona(s) que juegan 
ese papel, se vuelve prácticamente imposible identificar sus intenciones comunicativas, y en consecuencia al contenido constituido a partir de ellas. La respuesta de Marmor a este reto consiste en negar que el contenido asertivo de la enunciación de una oración esté dado por completo por las intenciones comunicativas de los hablantes. Según él, lo anterior se sigue de la observación empírica de que los hablantes podemos fallar y comunicar una cosa distinta de lo que intentamos. Si esto es así parece que para dar cuenta del contenido asertivo hace falta hablar, no (o no sólo) de los estados subjetivos del hablante (sus intenciones comunicativas), si no de un hecho objetivo: aquello que un escucha razonable habría entendido que el hablante quiso comunicar dadas las palabras que utilizó, los elementos del contexto, y otra información relevante que ambos comparten. Si esto es así, no hace falta ir buscar al hablante, o con mayor precisión a sus estados subjetivos intencionales, para atribuir un contenido asertivo a una enunciación. El resultado es que, en el contexto legislativo, no es necesario para atribuir un contenido asertivo a los actos de promulgación normativa (a los objetos que produce, no a la acción), encontrar ninguna intención comunicativa, basta con la reconstrucción que un escucha razonable llevaría acabo.

El argumento de Marmor es ciertamente sofisticado y, a primera vista, convincente. Sin embargo, desde mi punto de vista es ineficiente para superar una última objeción que el escéptico podría presentar. Marmor parece tener razón al decir que el criterio que sirve para determinar el contenido asertivo de una proferencia es objetivo, en el sentido de que no apela a la psicología particular de un individuo. Sin embargo, parece que este hecho objetivo está ineludiblemente ligado a uno subjetivo. Lo que un escucha razonable, conocedor de todos los hechos relevantes, habría entendido que intentaba comunicar el hablante, apela justa e invariablemente a la intencionalidad del hablante. Si no es posible en el caso de los actos legislativos reconocer a los hablantes, ¿qué intenciones comunicativas son las que un escucha racional habría buscado entender? Por supuesto que los escuchas cuentan con cierta evidencia (principalmente semántica y sintáctica) que podría guiarlos en dicha reconstrucción de las intenciones comunicativas, pero dudo mucho que Marmor esté dispuesto a 
Lenguaje y derecho: cuando la filosofía del derecho no es suficiente

aceptar que esta evidencia sirve a los escuchas de manera exhaustiva para reconstruir las intenciones comunicativas de los hablantes.

El capítulo dos es un intento por explicar la naturaleza y alcance del contenido comunicativo implicado por un acto asertivo en el contexto legal. Si la tesis presentada en el capítulo uno es correcta y los actos legislativos de promulgación de normas son similares a los actos asertivos que los hablantes llevan a cabo en contextos de comunicación ordinaria, en el sentido de que son de hecho actos de habla que comunican un cierto contenido (legal), y si es cierto además que en situaciones de comunicación ordinaria los hablantes comúnmente comunican más de lo que explícitamente expresan, parece natural asumir que al menos una parte del contenido comunicado en el contexto legal está dada implícitamente. Esta suposición es el punto de partida que utiliza Marmor para construir, a lo largo del capítulo, un argumento según el cual es difícil confiar en el contenido implicado por los actos de promulgación legislativa, dada la naturaleza estratégica del discurso legal. El capítulo se desarrolla de la siguiente forma: en la primera parte Marmor describe las dos maneras principales en las que, según él, se puede implicar un cierto contenido comunicativo a través de la proferencia de un enunciado. El siguiente paso en la argumentación es caracterizar, en términos generales, lo que Marmor llama discurso estratégico. La última parte pretende mostrar dos cosas, la primera que el discurso legal (al menos en lo que se refiere al derecho legislativo) es una forma de discurso estratégico, la segunda, que gracias a eso es difícil dar cuenta del contenido implicado por un acto de promulgación legislativa e incluso de revisión judicial.

Con mayor detalle, a menudo se habla del contenido implicado de una aserción para referirse al contenido al que, sin haber sido explícitamente formulado, queda comprometido un hablante en las circunstancias particulares de su proferencia. Decir de un hablante que está comprometido con un cierto contenido implicado quiere decir que para él está cancelada la posibilidad de retractarse o negar este contenido una vez hecha la proferencia. Si lo hiciera, un escucha razonable estaría justificado para considerar dicha negación como desconcertante, no genuina o incluso contradictoria. De acuerdo con Marmor, a pesar 
de que hay varios tipos de contenido implicado los dos más familiares son las llamadas implicaturas conversacionales y las presuposiciones.

Para explicar las implicaturas Marmor utiliza el bien conocido marco de la teoría de Herbert Paul Grice. Según Grice, nuestra habilidad para entender expresiones más allá de lo que se dice explícitamente radica en la combinación de dos factores: la existencia de normas conversacionales y el conocimiento compartido, por parte de los participantes de una conversación, de ciertas características del contexto conversacional. Comúnmente se acepta que las implicaturas son el resultado de inferencias derrotables que los hablantes llevan a cabo a partir de cierto contenido semántico, un determinado conocimiento contextual y de un cierto marco normativo. De acuerdo con Grice, cuando el propósito de una conversación es el intercambio cooperativo de información ciertas máximas son aplicables. Estas máximas facilitan la función cooperativa de las interacciones comunicativas que normalmente tienen lugar en nuestras conversaciones ordinarias. Grice propone las siguientes cuatro máximas de conversación ordinaria:

- Máxima de cantidad. De acuerdo con esta máxima los hablantes deben asegurarse de que sus contribuciones a la conversación sean tan informativas como sea requerido. Es decir, deben asegurarse de no decir ni más ni menos de lo necesario.

- Máxima de calidad. Según esta máxima los hablantes no deben decir aquello que creen que es falso y tampoco deben decir aquello para lo que no tienen evidencia adecuada.

- Máxima de relevancia. Esta máxima pide a los hablantes asegurarse de que sus contribuciones sean relevantes a la conversación.

- Máxima de cortesía. Se pide a los hablantes evitar la oscuridad y ambigüedad en sus contribuciones, así como ser ordenados y breves.

De acuerdo con Marmor estas máximas son normativas: por un lado los hablantes normalmente las siguen durante sus conversaciones ordinarias; por otro, están apoyadas por razones que las convierten en las normas que los hablantes deben seguir con el fin de realizar su propósito de llevar a cabo un intercambio cooperativo de información. 
Con este marco normativo en mente podemos llegar a una descripción un tanto más detallada de lo que es una implicatura conversacional. Decimos, pues, que un contenido es implicado conversacionalmente por un hablante si no es parte de lo que el hablante dijo, pero es parte de lo que comunicó en la ocasión particular de su aserción, dadas las máximas conversacionales que rigen los contextos de conversación ordinaria.

Es importante señalar aquí que, aunque afirma estar siguiendo a Grice, Marmor reconstruye la idea de implicatura de una manera un tanto alejada (sin llegar a ser contradictoria o inconsistente) de la forma en la que generalmente se piensa esta figura en filosofía y lingüística. Por ejemplo, para Wayne Davis (2014) una implicatura "denota o bien (i) el acto de significar o implicar una cosa al decir una cosa distinta, o (ii) el objeto de ese acto". Si bien es cierto que nada de esto contradice lo dicho por Marmor, parece verdad también que esta caracterización de las implicaturas resulta, por lo menos, más informativa. Desde este punto de vista, las implicaturas no son solo inferencias que los miembros de una conversación pueden derivar a partir de lo que se dice, si no inferencias cuyo contenido difiere del contenido explícitamente enunciado por el hablante. La diferencia es más clara si pensamos en el ejemplo de implicatura conversacional proporcionado por Davis quien nos pide imaginar el siguiente diálogo:

\section{Alan: ¿Irás a la fiesta de Paul? \\ Barb: Tengo que trabajar}

Según él, este es un claro ejemplo de un hablante que utiliza un enunciado para significar algo distinto de lo que el enunciado (convencionalmente) significa. Barb quiere decir que no irá a la fiesta, pero lo hace utilizando un enunciado que comúnmente significa que tiene trabajo. Dado que Barb nunca dijo que no iría a la fiesta y sin embargo eso es lo que quiso decir, podemos afirmar que lo implicó. Como puede observarse, desde este punto de vista una de las características fundamentales de las implicaturas es que su contenido varía del contenido que usualmente suele adscribirse al enunciado a través del cual se expresan. Ciertamente sería equivocado decir que el argumento de Marmor con 
respecto a la práctica de promulgación de leyes fracasa porque su caracterización de las implicaturas conversacionales se aleja de la ortodoxia filosófica. No obstante, conviene por lo menos tener presente la diferencia entre su manera de caracterizar esta forma del contenido implicado de la proferencia de un enunciado y la forma en la que comúnmente se habla de implicaturas conversacionales entre filósofos.

De acuerdo con Marmor, la segunda forma en la que se puede implicar cierto contenido comunicativo a partir de la enunciación de una oración es la presuposición. Según él, una presuposición es aquel contenido comunicativo que, a pesar de no haber sido enunciado, debe tomarse por garantizado para que el contenido enunciado o su relevancia tengan sentido. El contenido implicado por una presuposición es el contenido que los miembros de una conversación de hecho comparten desde el inicio o que estarían dispuestos a acomodar conforme la conversación avanza. Los ejemplos propuestos por Marmor para entender esta idea son los siguientes:

1) "Bill se arrepiente de haberle mentido a sus padres".

Donde la presuposición es: Bill [cree que él] mintió a sus padres.

2) "Sara olvidó recoger a Jane en el aeropuerto".

Donde la presuposición es: Se suponía que Sara recogería a Jane en el aeropuerto.

3) "La esposa de John va a ir al concierto mañana".

Donde la presuposición es: John está casado.

Por último, Marmor llama la atención acerca de las llamadas implicaciones semánticamente codificadas. Como la expresión parece sugerir, estas son implicaturas que provienen del significado de las palabras utilizadas en el enunciado expresado. Algunos ejemplos ofrecidos por Marmor son:

(4) "incluso X puede hacer A" (donde se implica que hay algunos otros, además de $\mathrm{X}$, que pueden hacer $\mathrm{A}$, y que $\mathrm{A}$ es entre ellos uno de los que menos probabilidad tiene de hacer $\mathrm{A}$ ).

(5) "X logró encontrar a A" (donde se implica que era de esperarse que encontrar a A fuera complicado). 
Que el contenido implicado por la aserción de estos enunciados está semánticamente codificado es evidente, según Marmor, si observamos la imposibilidad que afecta al hablante de cancelarlo. Esto es, la proferencia de un enunciado como (5) perdería todo sentido si de pronto el hablante de dicha proferencia afirmara que encontrar a A era en realidad sencillo. Supuestamente, hay un cierto contenido que sin ser explícito está codificado en el término "lograr" y que es parte del contenido que un hablante comunica al enunciar (5). Marmor afirma entonces que el criterio para distinguir entre el contenido implicado semánticamente codificado y no semánticamente codificado está dado por la posibilidad o imposibilidad de su cancelación.

Aunque general, la caracterización anterior de la primera parte del capítulo dos es suficiente para entender el argumento acerca del discurso jurídico que Marmor pretende ofrecer posteriormente.

La sección dos del capítulo, que coincide con el segundo paso en la argumentación, consiste en describir lo que Marmor llama el discurso estratégico. Para entender qué es el discurso estratégico es necesario primero tener claro que no en todos los contextos en los que una conversación tiene lugar, los hablantes persiguen el propósito de intercambiar información cooperativamente. En otras palabras, en ciertas ocasiones el propósito de una conversación no es el intercambio de información. Los ejemplos citados por Marmor son las conversaciones de cortesía, en las que los hablantes intercambian expresiones sin el propósito de que estas sean informativas o incluso verdaderas. En estos casos los miembros de una conversación buscan simplemente expresar su conformidad con una convención social. Cuando una persona te pregunta si te ha gustado la película que te recomendó semanas atrás y respondes que sí, puede que lo hagas sin la intención de reportar algo verdadero, sino simplemente de ser cortés con los demás. Es importante señalar que en todos estos ejemplos, los intercambios que los hablantes llevan a cabo son cooperativos incluso si no son "confiables". Con exactitud, la idea aquí no es que en ocasiones los hablantes no son cooperativos en sus interacciones conversacionales, sino que la cooperación comunicativa es una cuestión de grado. Hay contextos, como esos de conversación ordinaria, en los que se requiere un grado superior de cooperación a fin 
de lograr el objetivo de la conversación misma: el intercambio confiable de información. Hay otros contextos en los que el objetivo de la conversación, ajustar el comportamiento propio a las convenciones sociales, permite un grado de cooperación menor.

Hemos sugerido, siguiendo a Marmor, que en un extremo de la cooperación comunicativa se encuentran los contextos de conversación ordinaria. En el extremo contrario se encuentra la manipulación. Según Marmor estos son contextos conversacionales en los que los hablantes (al menos uno de ellos) afirman algo verdadero con la intención de implicar algo que sabe que es falso. Por ejemplo, una persona que se presenta en un hospital como el "Dr. X" a pesar de que su grado de doctorado no pertenece a ninguna de las ciencias médicas.

Entre esos dos extremos se encuentra el discurso estratégico. La característica primordial de este tipo de conversaciones es que los hablantes intentan con sus locuciones obtener una ventaja al implicar más (o menos) de lo que estarían dispuestos a hacer explícito. La razón por la que un hablante estaría interesado en no hacer explícito aquello que ha intentado implicar es que, de hacerlo, dirigiría al fracaso el propósito de su afirmación. El ejemplo que ofrece Marmor para entender mejor esta idea es la insinuación. Según él, cuando los hablantes intentan insinuar algo, estarían fracasando si aquello que buscan insinuar fuera parte del contenido explícito de su aserción. Por el contrario, en contextos de conversación ordinaria los hablantes no verían afectado el propósito de su aserción si el contenido implícito se hiciera explícito en algún momento. Cuando se trata de conversaciones estratégicas, los escuchas pueden también no estar dispuestos a aceptar el contenido implícito de la preferencia de un enunciado. El caso de un niño que pretende no haber entendido el contenido que su madre buscaba implicar al responder "has comido muchos dulces el día de hoy" ante la pregunta "ipuedo comer chocolate?", es un buen ejemplo de esto.

El discurso estratégico se hace posible bajo ciertas circunstancias. Es necesario que exista cierto nivel de incertidumbre con respecto al marco normativo que gobierna la conversación para que los hablantes consigan realizar su propósito de obtener alguna ventaja a partir del contenido que su aserción implica. Marmor afirma que, cuando las 
conversaciones no tienen el propósito de ser completamente cooperativas, los hablantes no siguen las máximas de conversación descritas por Grice. Si lo hicieran, su propósito de obtener alguna ventaja se vería frustrado. Hay dos tipos de incertidumbre normativa que facilitan el desarrollo de una conversación estratégica o, con mayor precisión, de un movimiento estratégico en una conversación: incertidumbre acerca de las reglas que los hablantes deben seguir; incertidumbre acerca del grado de adherencia a las reglas que se espera por parte de los hablantes.

En la última parte del capítulo, Marmor busca mostrar que el discurso jurídico, en particular el discurso legislativo o de creación de leyes y el discurso judicial, son instancias del discurso estratégico, y cómo, si esto es cierto, se sigue que el contenido implicado por un acto de habla legislativo es poco confiable.

Marmor nos pide distinguir entre dos tipos de conversación que tienen lugar durante el proceso legislativo. La primera es la conversación entre legisladores antes de la promulgación de una ley. La segunda se da entre el resultado de esa primera conversación (un acto de habla colectivo) y aquellos a quienes la ley se dirige, normalmente con las cortes como intermediarios. Marmor afirma que ambos tipos de conversación son estratégicos. La idea es que hay un interés compartido por las legislaturas y las cortes por mantener cierto grado de indeterminación comunicativa, dado que esto les permite realizar sus propósitos. Según él, el propósito de las legislaturas es facilitar acuerdos y compromisos que les permitan realizar su trabajo legislativo. Para conseguir este propósito es necesario que la conversación interna se desarrolle en términos estratégicos. Si los legisladores tuvieran claridad acerca del contenido que aquellos que defienden una agenda distinta pretenden implicar mediante los documentos que someten a votación, posiblemente rechazarían cualquier propuesta que llegara a sus mesas. Por otro lado, las cortes también están interesadas en transmitir mensajes indeterminados, a fin de que las legislaturas les permitan un margen de acción mayor que les facilite el ejercicio con mayor discrecionalidad. En pocas palabras, Marmor sostiene que el propósito que caracteriza la manera en la que ambos organismos se insertan en una conversación es un deseo por acaparar la mayor cantidad de poder posible. 
Ciertamente el capítulo pierde en esta sección buena parte de la claridad expositiva que caracteriza a las primeras dos. Además, aunque es fácil detectar las afirmaciones alrededor de las cuales se construye esta parte del texto, es difícil ubicar los argumentos que las respaldan. Por otro lado, la argumentación avanza sin demasiado orden señalando características de cada uno de los tipos de conversación descritos anteriormente. Es cierto que estos problemas son fáciles de superar si el lector es suficientemente paciente, sin embargo, existen dificultades a nivel argumentativo difíciles de pasar por alto. Por ejemplo, aunque Marmor se esfuerza por presentar la afirmación de que en los distintos contextos de interacción entre la legislatura y las cortes se lleva a cabo una conversación estratégica, como si fuera una consecuencia conceptual del propósito que persigue cada uno de estos organismos, lo cierto es que una afirmación así parece más bien empírica. Sostener que los legisladores están interesados en ocultar parte de lo que intentan comunicar parece más una tesis que podríamos contrastar con las intenciones actuales de los miembros de una legislatura, y no una tesis conceptual acerca de la mejor manera de conseguir el propósito que supuestamente persigue la actividad legislativa. Mas aún, los propósitos que atribuye Marmor a las cortes y legislaturas dista de ser obvio, y parece más bien arbitrario. Es relativamente sencillo encontrar descripciones alternativas que, intuitivamente, resultan igualmente plausibles. Uno podría decir, por ejemplo, que el propósito de los jueces es llevar a cabo las funciones que legalmente les han sido encomendadas. Seguramente, será difícil encontrar en el catálogo de funciones algún indicador que apunte hacia el aseguramiento de suficiente poder, o algo por el estilo. Si el lector no comparte las intuiciones acerca de las finalidades que caracterizan a las legislaturas y a las cortes, será difícil encontrar en el texto un argumento o evidencia útiles para persuadirlo.

En el capítulo tres Marmor ofrece un argumento a favor de la tesis de que las prescripciones jurídicas, por lo menos aquellas que forman parte del derecho legislado, son el tipo de acto de habla que expresa un contenido que puede ser verdadero o falso. Que las prescripciones legales expresen este tipo de contenido es importante porque, de no hacerlo, sería imposible atribuir validez a las inferencias que llevamos 
a cabo con ellas. En otras palabras, la argumentación de Marmor está motivada por la siguiente preocupación: los agentes jurídicos cotidianamente llevan a cabo inferencias a partir de las prescripciones que encuentran en el derecho legislado; nos interesa que dichas inferencias sean válidas, es decir, que la verdad de la conclusión esté asegurada por la verdad de las premisas; es condición necesaria de la validez de una inferencia que las afirmaciones que la componen sean susceptibles de ser verdaderas o falsas; por tanto, es importante explicar cómo es posible que las prescripciones legales expresen el tipo de contenido que puede ser verdadero o falso.

El argumento de Marmor es el siguiente. En primer lugar, hay que distinguir entre, por lo menos, dos tipos de actos de habla performativos, regularmente expresados por enunciados imperativos con distintas formas. Aquellos a los que Marmor llama exhortativos son actos de habla que buscan motivar la conducta de las personas a quienes están dirigidos mediante la mera enunciación, con la expectativa de que esta sea reconocida por sus destinatarios como una razón para la acción. Un ejemplo es la expresión de una persona dirigiéndose a otra diciendo "escribe todo lo que escuches". Por otro lado, existen enunciados imperativos que, cuando son expresados, buscan igualmente motivar la conducta de aquellos a los que se dirigen, pero que contienen el operador "deber". Por ejemplo, una persona que se dirige a otra diciendo "debes escribir todo lo que escuches". De acuerdo con Marmor, la inclusión del operador "deber" en este caso sugiere que existen razones independientes, distintas a la enunciación misma, para llevar a cabo la acción solicitada. Las instrucciones jurídicas, parece claro, son actos de habla del primer tipo, es decir, exhortativos. Esto es, las prescripciones legales buscan motivar la conducta de los sujetos y que sea el solo hecho de su pronunciación el que les conceda razones para la acción.

El siguiente paso en la argumentación, como es de esperarse, consiste en mostrar que los exhortativos son el tipo de acto de habla que expresa contenidos susceptibles de ser verdaderos o falsos. Aunque existen diversos tipos de actos de habla exhortativos, y estos son expresados por distintos tipos de enunciados, Marmor se concentra en los imperativos. Es importante señalar que usualmente el contenido del 
que se predica verdad o falsedad con respecto a la expresión de un enunciado es el llamado contenido proposicional. Una manera natural de interpretar el contenido proposicional de un imperativo, según Marmor, es sugerir su carácter autorreferencial. En pocas palabras, el contenido proposicional de los imperativos es autorreferencial. Esto quiere decir que cada vez que una persona expresa un imperativo del tipo "cierra la puerta", el contenido proposicional está dado por los deseos del hablante: su deseo de que $\mathrm{X}$ cierre la puerta y su deseo de que $\mathrm{X}$ reconozca la expresión de ese deseo como una razón para la acción. De este modo, el contenido proposicional del enunciado "cierra la puerta" expresado por $\mathrm{P}$ y dirigido a $\mathrm{S}$ es "P quiere/desea que $\mathrm{S}$ cierre la puerta y quiere/desea que reconozca la expresión de dicho deseo como una razón para realizar esa acción". Este es claramente un contenido proposicional descriptivo (como cualquier otro) acerca de un estado mental particular de un sujeto singular. Dado que el contenido proposicional expresado por un imperativo es autorreferencial, siempre que la expresión sea sincera, el contenido será verdadero. En otras palabras, la simple expresión de un enunciado imperativo hace verdadero su contenido proposicional. El contenido proposicional expresado por un imperativo solo puede ser falso en caso de insinceridad o cuando las circunstancias particulares de la conversación son suficientemente anormales (por ejemplo, si te pido cerrar una puerta en medio del bosque donde no hay puertas).

E1 siguiente paso en el argumento de Marmor consiste en mostrar que este análisis del contenido proposicional de los exhortativos funciona igualmente bien para el caso jurídico. Con este fin, Marmor propone distinguir entre los deseos que la gente tiene a nivel personal y los deseos que adquieren derivados de su papel como funcionarios. Los exhortativos expresados por el derecho legislativo son exhortativos oficiales; es decir, "reflejan los deseos e intenciones de las personas en sus funciones de servidores públicos, en tanto servidores públicos" (71). Es importante señalar que, al hablar de los exhortativos oficiales, Marmor introduce por primera vez la idea de intención como parte del contenido proposicional de un acto de habla exhortativo. Anteriormente, recordemos, el contenido proposicional de estos actos estaba dado exclusiva- 
mente por los deseos del hablante. Otra cosa que vale la pena mencionar es que Marmor no señala cuál es el tipo de intención al que se refiere exactamente. Desafortunadamente, como veremos más adelante, el argumento se beneficia del carácter polisémico de esta expresión.

La siguiente complicación a la que intenta hacer frente el argumento tiene que ver con la naturaleza colectiva de los actos legislativos. Dado que las legislaturas están integradas por más de un individuo, es difícil establecer quién (quiénes) es (son) el sujeto (los sujetos) cuyos estados mentales están reflejados en el contenido proposicional de una prescripción jurídica. Para superar este reto, Marmor se vale de la idea, sugerida en el capítulo uno, de que el contenido proposicional de un acto de habla (colectivo) consiste en lo que se dice (el contenido asertivo) en un contexto determinado, y no por lo que el hablante intentó decir. Para defender esta idea, Marmor apela una vez más a la necesidad de dejar abierta la posibilidad para los hablantes de fallar al comunicar todo lo que intentan. Si esto es así y de hecho estas fallas tienen lugar, parece que el contenido de una expresión debe ser determinado, no por lo que el hablante quiso decir, sino por lo que el hablante de hecho dijo, lo cual, recordemos, está dado por lo que un escucha razonable habría entendido dada la expresión enunciada por el hablante, el contexto y el conocimiento común de ciertas presuposiciones.

Lo anterior no puede ser más desconcertante. En primer lugar, la sugerencia de Marmor o bien implica la identidad entre el contenido asertivo y el contenido proposicional de una oración, o bien cambia el objeto de estudio del segundo hacia el primero. El problema con la primera de estas opciones es que, al día de hoy, que el contenido proposicional de una oración sea equivalente al contenido asertivo de la enunciación de una oración es una cuestión controversial en filosofía del lenguaje. Para algunos filósofos es posible atribuir un contenido proposicional a ciertos enunciados, a pesar de no haber sido jamás expresados por hablante alguno en ningún contexto, es decir, sin que se les pueda atribuir un contenido asertivo. Por ejemplo, algunos enunciados de la matemática. El problema con el argumento de Marmor es que resulta totalmente silente ante esta preocupación. Por otro lado, si el contenido proposicional de una oración y el contenido asertivo de su 
enunciación son distintos, es difícil observar, o por lo menos Marmor no es explícito al respecto, cómo una característica del segundo es útil para superar una dificultad explicativa en relación con el primero. Es decir, sirve de poco saber que el contenido asertivo de una enunciación está determinado por lo que se dice (más el contexto) y no por las intenciones del hablante, cuando lo que nos interesa saber es cuáles son los estados mentales que determinan el contenido proposicional de un exhortativo oficial colectivo.

En segundo lugar (concedamos que no existe diferencia entre el contenido proposicional y el contenido asertivo), Marmor parece utilizar el término "intención" de dos maneras distintas para favorecer su argumento. Por un lado, al hablar del contenido proposicional de un exhortativo simple, "intención" parece denotar un deseo, en particular, el deseo de que alguien lleve a cabo una acción. Esto es, cuando digo "cierra la puerta" expreso mi intención de que cierres la puerta. Sin embargo, al hablar del contenido asertivo de la enunciación de una oración, "intención" parece denotar la intención de comunicar un contenido particular: la intención comunicativa del hablante. Al decir "cierra la puerta" tengo la intención de comunicar mi intención de que cierres la puerta. Si esto es así, nada que se pueda decir acerca de las intenciones (comunicativas) de los hablantes responde aún a la pregunta por las intenciones (deseos) expresadas por un exhortativo colectivo.

Si mis observaciones son correctas, se sigue que la respuesta de Marmor ante la preocupación derivada del carácter colectivo de las legislaturas encargadas de promulgar las prescripciones jurídicas que integran el derecho legislativo no es satisfactoria. Es falso que el argumento haya logrado superar el reto que impone la objeción según la cual es imposible identificar a los sujetos cuyos estados mentales (deseos/intenciones) forman el contenido proposicional de un exhortativo oficial colectivo. De lo anterior, se sigue que el contenido proposicional de las instrucciones jurídicas no es como el contenido proposicional de los exhortativos simples. De nueva cuenta, carecemos de una explicación que nos permita dar cuenta del contenido proposicional de las prescripciones jurídicas y, con ello, de la posibilidad de llevar a cabo inferencias con ellas. 
Lenguaje y derecho: cuando la filosofía del derecho no es suficiente

En el capítulo cuatro, Marmor se ocupa del problema de la vaguedad en el derecho. Su propósito es presentar una taxonomía de los distintos casos de vaguedad que aparecen en la práctica jurídica y explicar sus racionales. El capítulo está divido en dos partes. En la primera, Marmor distingue entre distintos tipos de vaguedad que surgen con relación a los términos de un lenguaje natural. En la segunda, explora la manera en la que estos casos se presentan en el contexto legal.

Claramente, es fundamental, antes de comenzar esta clasificación, caracterizar el fenómeno de la vaguedad en el lenguaje. La vaguedad, dice Marmor, es un aspecto particular de la relación que existe entre las palabras y los objetos designados por ellas. Para entender qué es la vaguedad conviene caracterizar antes la extensión definida y la no extensión definida de un término. Comúnmente, entendemos por "extensión de un término" el conjunto de objetos (actuales, posibles, presentes, pasados y futuros) designados por él. Así, la extensión definida de un término es el conjunto de objetos que claramente designa. De modo similar, su no extensión definida es el conjunto de objetos que el término claramente no designa. La vaguedad surge cuando nos encontramos frente a un caso límite, casos en los que un objeto particular no forma parte ni de la extensión definida ni de la no extensión definida de un término. En otras palabras, en estos casos no existe una respuesta correcta ante la pregunta sobre si un objeto particular pertenece a la extensión de un término, o si es parte de su no extensión.

Entre las distintas formas de vaguedad que existen, el primer caso que Marmor distingue es el de aquellos términos obvia o transparentemente vagos. Palabras como "calvo", "alto", "rico" son términos que con gran facilidad y claridad dan lugar a la existencia de casos límite.

Existen otros términos que también dan lugar a la vaguedad, pero lo hacen de manera menos clara como "entrar". Para ilustrar lo anterior, imaginemos que existe una prohibición de entrar a un cierto lugar con animales; imaginemos que nos encontramos cerca de la entrada con nuestra mascota atada a nosotros por una correa; imaginemos que la extensión de la correa es suficiente como para permitir a uno ingresar al lugar sin que el otro se mueva de su posición original; ahora imaginemos que, mientras esperamos a un amigo, nuestra mascota 
ingresa en el lugar, o que nosotros ingresamos en el lugar pero nuestra mascota permanece afuera, ¿diríamos que hemos entrado con una mascota al lugar?

El tercer tipo de vaguedad identificada por Marmor es aquella a la que llama, siguiendo a Timothy Endicott ${ }^{2}$, vaguedad extravagante. A diferencia de los otros casos en los que la característica semántica principal que da lugar a la vaguedad es la presencia de casos límite, en los casos extravagantes la característica principal es que la aplicación de estos términos implica una evaluación multidimensional acerca de (por lo menos algunos) elementos constitutivos inconmensurables. Por ejemplo, si nos preguntamos por el predicado "bello" veremos que los elementos que debemos tomar en cuenta para determinar el alcance de su extensión son imposibles de comparar, por ejemplo, la abstracción en contra de la técnica, la técnica en contra del valor expresivo, el valor expresivo en contra de la originalidad, etc.

Otra manera de entender la diferencia entre casos de vaguedad ordinaria (transparente o no) y la vaguedad extravagante es que, para los términos del primer tipo, es más bien sencillo llegar a precisar los contornos de su extensión introduciendo un límite discrecional, aunque no arbitrario. En cierto contexto podríamos establecer que quien tuviera menos de cien mil cabellos en la cabeza cuenta como calvo y que quien tuviera más no. Por lo menos en ese contexto, la vaguedad inherente al término calvo habría sido superada. El caso es distinto para los términos extravagantemente vagos. Es simplemente imposible, dada la complejidad e inconmensurabilidad de los criterios que deben tomarse en cuenta para establecer su extensión, asignar un límite discrecional. Pensemos en el ejemplo de "belleza", tendríamos que decir algo como: lo bello es aquello cuyo valor expresivo es el doble con respecto a su nivel de abstracción y su originalidad rebasa en tres cuartas partes el valor de la técnica, etc., lo cual ciertamente parece una empresa poco prometedora.

2 Endicott, T., "The Value of Vagueness", en Vagueness in Normative Texts, Vijay K. Bhatia, Jan Engberg, Maurizio Gotti, yDorothee Heller (eds.), Bern: Peter Lang, 2008, pp. 24-25. 
Lenguaje y derecho: cuando la filosofía del derecho no es suficiente

Por último, Marmor presenta un caso de vaguedad no semántica. La vaguedad pragmática, como la llama, surge en virtud no del significado de las palabras que contiene una expresión, puesto que sobre eso (e incluso sobre su contenido asertivo) no existe ninguna duda, sino en virtud de la información que dichas palabras proveen relevancia a un contexto. Es decir, la vaguedad pragmática tiene que ver con la existencia de casos límite acerca de la relevancia de la contribución a la conversación por parte de los hablantes. De manera similar, aunque en la dirección opuesta, en ocasiones el contexto ofrece información suficiente para que expresiones que contienen términos incluso transparentemente vagos sean precisas. Por ejemplo, cuando hablo de la persona alta, refiriéndome a la persona que se encuentra junto a otra que claramente no lo es.

En el lenguaje jurídico la vaguedad puede surgir en diversos contextos: la legislación, documentos administrativos, la Constitución. Marmor se concentra en la interpretación de los textos legislativos. La vaguedad suele surgir porque la ley contiene alguna expresión relevante vaga en alguno de los sentidos de vaguedad anteriormente mencionados. Así, el caso paradigmático de vaguedad en el derecho surge al intentar aplicar una prescripción legal a un caso límite de la extensión de uno de los términos generales que contiene.

Justo de esta forma es que surgen los casos de vaguedad ordinaria en el derecho. Como Marmor, para ilustrar este punto utilizaré el bien conocido ejemplo de Hart sobre una ley que prohíbe la entrada de vehículos a un parque público. La vaguedad inherente al término general "vehículo" se hace evidente cuando, por ejemplo, una persona intenta ingresar al parque con una carreola. No es evidente que la norma que prohíbe vehículos en el parque deba ser aplicada, justamente porque una carrerola es un caso límite de la extensión del término "vehículo". Sea como fuere, encontrar una solución a casos como este mediante la interpretación de este tipo de expresiones no es una tarea extremadamente complicada. De acuerdo con Marmor, la mayoría de las veces el contexto en el que fue promulgada una ley, su propósito, u otros factores pragmáticos similares pueden determinar una respuesta. Para continuar con nuestro ejemplo, si el propósito de la norma era evitar 
el ruido y la contaminación al interior del parque, parece que tomar una decisión sobre si una carreola es o no un vehículo se vuelve una cuestión más bien sencilla. De cualquier forma, en ocasiones, cuando la información provista por el contexto y otros factores pragmáticos no es suficiente para superar los casos de vaguedad, las cortes tienen cierta libertad para postular un criterio discrecional, aunque no arbitrario, que resuelva la cuestión para ese caso y otros similares en el futuro.

La vaguedad transparente u obvia, como era de esperarse, difícilmente aparece en el lenguaje legislativo. Las legislaturas, por lo regular, son cuidadosas de no incluir términos que transparentemente dan lugar a casos límite como "alto", "rico", "calvo", etc. No obstante, en ocasiones los legisladores incluyen esta clase de expresiones en las prescripciones que promulgan. Casi siempre acompañados de otras regulaciones mucho más precisas, la inclusión de expresiones obviamente vagas en los textos legislativos tiene el propósito de permitir a las cortes un espacio delimitado de libertad que les permita incluir en el ámbito de aplicación de una norma conductas que, como consecuencia de una precisión exhaustiva, podrían quedar no reguladas.

Por último, los términos extravagantemente vagos aparecen con marcada frecuencia en los textos jurídicos. Según Marmor, lo anterior es una consecuencia del interés de las legislaturas de delegar en las cortes, por buenas razones, la toma de decisiones. Dado que utilizar correctamente estos términos, como hemos visto, involucra la interacción de diversos factores inconmensurables, encontrar delimitaciones precisas a su ámbito de aplicación no es tarea sencilla. La única opción aparentemente disponible para tomar una decisión razonable cuando se trata de una prescripción jurídica que contiene un término así de complejo y ninguno de los factores en juego es evidentemente sobresaliente es llevar a cabo un juicio holístico todas las cosas consideradas. Marmor concede que no existen criterios últimos de razonabilidad o corrección cuando se trata de resolver este tipo de ambigüedad; sin embargo, confía en que la evaluación que pueden realizar las cortes caso por caso, a través de la búsqueda de un juicio de ese tipo, es la manera correcta de lidiar con esta clase de ambigüedad. 
Lenguaje y derecho: cuando la filosofía del derecho no es suficiente

El capítulo cuatro es modesto en sus propósitos y afirmaciones. Ningún argumento profundamente controversial o afirmación notoriamente provocadora es presentada en esta parte del libro. Sin embargo, el capítulo falla en ofrecer una reconstrucción exhaustiva de los casos de vaguedad en el derecho (aunque también es cierto que Marmor jamás afirma explícitamente que ese sea su propósito). Incluso si nos concentramos en los casos de interpretación judicial, como hace Marmor, el texto deja un tipo de vaguedad sin observar. Esta es la vaguedad llamada comúnmente de re. En términos muy generales, este tipo de vaguedad no se origina en la relación entre un término y su extensión, sino en una cierta propiedad que algunos objetos poseen. La propiedad, digamos, de tener contornos (o una constitución) indeterminados. Un ejemplo es el monte Everest. Mientras que con precisión el término "Monte Everest" se refiere a la montaña ubicada en las coordenadas $27^{\circ} 59^{\prime} 17^{\prime \prime}$ Norte Latitud y $86^{\circ} 55^{\prime} 31^{\prime \prime}$ Este Longitud, los contornos precisos de dicho objeto no son del todo claros. Así, tiene sentido decir que el término "Monte Everest" es vago, aunque como hemos visto esto poco tiene que ver con la existencia de casos límite en relación con su extensión.

En ocasiones, la interpretación del derecho legislativo no es indiferente a este tipo de vaguedad. Imaginemos que una ley designa a una cierta estatua patrimonio cultural de un país. En este país existe además otra ley que prohíbe la modificación, entre otras cosas, de aquellos bienes declarados patrimonio cultural. Ahora imaginemos que para conmemorar el aniversario cien de una fecha importante en ese país relacionada con la estatua, se ha decidido colocar una placa en la base que la sostiene. La pregunta que surge es ¿forma parte de la estatua la base sobre la que se encuentra? Si la respuesta es afirmativa, colocar la placa conmemorativa está prohibido, si la respuesta es negativa entonces está permitido. Posiblemente estos casos no son tan comunes en la práctica jurídica como lo son los casos de vaguedad lingüística, pero dada su distinta naturaleza, reclaman una explicación particular que Marmor falla en aportar.

Los últimos dos capítulos tienen por tema la interpretación de textos jurídicos. El capítulo cinco ofrece un análisis sobre la interpretación 
de textos legislados, mientras que el capítulo seis se concentra en la interpretación de textos constitucionales.

La estrategia de Marmor en el capítulo cinco es presentar un argumento en contra de la llamada doctrina textualista de la interpretación judicial. Según él, es importante, en cualquier análisis lingüístico del derecho legislativo, concentrarse en el también llamado textualismo justamente porque este pretende tomar a aquel como punto de partida. Es decir, el textualismo, en tanto teoría de la interpretación judicial, sugiere que la manera correcta de interpretar el derecho consiste en encontrar lo que de hecho dice la ley; para ello, según el textualista, es suficiente y necesario llevar a cabo un análisis lingüístico de las prescripciones jurídicas tal y como fueron promulgadas. El argumento de Marmor procede de la siguiente manera: después de presentar qué es el textualismo, explica cuál es el punto de vista particular acerca del lenguaje y la comunicación adoptada por esta teoría, para después mostrar porqué la adopción de estas ideas vuelve al textualismo poco útil para explicar la interpretación judicial.

Antes de reconstruir su argumento en contra de la doctrina textualista, es conveniente dar cuenta de la manera en la que Marmor concibe la actividad interpretativa en el derecho. En términos generales, sostiene que es necesario interpretar en el derecho solamente cuando algo no es suficientemente claro; es decir, cuando hay alguna duda razonable acerca de la manera de entender lo que la ley prescribe. Los casos que dan lugar a interpretación son dos: cuando existe una duda plausible acerca de lo que los legisladores de hecho dijeron o implicaron en la ley; cuando la intención comunicativa de una directiva jurídica es clara, pero existe una duda plausible acerca de la aplicación a un caso particular del contenido de una ley.

Como vimos, en la reconstrucción de Marmor, el textualismo sostiene que cuando los jueces se enfrentan a un problema de interpretación lo que deben hacer es concentrarse en lo que de hecho la provisión jurídica dice (e implica). Sumado a esto, el textualista está comprometido con la idea de que lo que la ley dice (el contenido asertivo de la ley) está determinado por lo que una persona razonable, suficientemente informada y con conocimiento suficiente del contexto jurídico y del 
Lenguaje y derecho: cuando la filosofía del derecho no es suficiente

caso, habría inferido a partir de las palabras expresadas en la ley, en el momento particular de su promulgación. ¿Qué tan útil es una teoría como esta para resolver problemas de interpretación judicial? Marmor sostiene que poco útil. La razón es que en el derecho la necesidad de interpretar la ley pocas veces surge a raíz de una duda plausible acerca del contenido asertivo de la provisión legal relevante. En la mayoría de las ocasiones, afirma, es necesario interpretar porque lo que la ley dice es de hecho insuficiente para determinar una solución al caso en cuestión. El argumento en contra del textualismo consiste, entonces, en señalar cuáles son los tipos de problemas que regularmente enfrentan los jueces que hacen surgir la necesidad de interpretar en el derecho, y ver si el textualismo puede dar cuenta de ellos. Los problemas son: vaguedad, conflictos normativos, ambigüedad y polisemia, y el contenido implicado.

La razón por la que el textualismo es incapaz de ofrecer una explicación aceptable de lo que los jueces deberían hacer al interpretar cualquier ley que da lugar a vaguedad (cualquiera de los tipos caracterizados en el capítulo cuatro) es precisamente que el lenguaje no ofrece respuestas. Si el textualismo busca comprometer a los jueces a buscar la respuesta a una pregunta interpretativa exclusivamente en los recursos ofrecidos por el leguaje, y la vaguedad es justamente un fenómeno que pone de manifiesto la limitación de esos recursos, la conclusión obvia es que el textualismo es incapaz de ofrecer una solución a los casos de este tipo.

Por otro lado, los conflictos normativos surgen en el derecho cuando distintas prescripciones demandan la realización de conductas incompatibles a la misma persona bajo las mismas circunstancias. Imaginemos el caso de dos leyes que piden a distintas clases de sujetos la realización de dos acciones que no pueden llevarse a cabo de manera conjunta. Imaginemos ahora el caso de un individuo que pertenece a ambas clases. El derecho le requiere realizar una acción, y el derecho también le requiere realizar otra acción, pero realizar una hace imposible realizar la otra. Cuando un problema así surge es necesario interpretar la ley, pero nada de lo que la ley dice nos puede servir como guía para este proceso interpretativo. Es justamente porque de todo lo 
que la ley dice, claramente, ha surgido este problema. Una vez más, el textualismo parece carecer de herramientas para explicar este caso interpretativo.

Ambigüedad y polisemia son dos fenómenos que, como la vaguedad, conducen a la indeterminación lingüística de una expresión. En pocas palabras, los casos de ambigüedad surgen con respecto a expresiones que tienen más de un significado. Existen dos tipos de ambigüedad: sintáctica y léxica. La segunda tiene que ver con términos que poseen dos significados distintos y no relacionados; por ejemplo, el término "banco" que en español se utiliza para referirse a un objeto utilizado para sentarse, a un cardumen o a una institución financiera. La ambigüedad sintáctica, en cambio, surge como consecuencia de la forma particular en la que las palabras están ordenadas en una oración. Por ejemplo, en la oración "Anoche estaba en el parque con mi telescopio y vi a Bob", no es claro si lo que deseo comunicar es que vi a Bob a través del telescopio, o si más bien nos encontramos en el parque mientras intentaba ver las estrellas. Marmor acepta que la ambigüedad no representa un problema tan importante para el textualista. Regularmente, el contexto ayuda a desambiguar expresiones ambiguas, por lo que la sugerencia textualista de ir a buscar en el contexto de promulgación el sentido particular de una expresión fue proferida, responde satisfactoriamente el problema. Como sea, Marmor cree que estos casos surgen con poca frecuencia en el derecho, y que los casos realmente comunes son los de polisemia. Según Marmor, los casos de polisemia son aquellos en los que los objetos o propiedades dentro de la extensión definida de un término varían de conformidad con las circunstancias de la expresión que lo contienen. Con mayor precisión, los casos de polisemia son aquellos en los que, dependiendo de ciertas características particulares del contexto en el que son expresados y de las intenciones de los hablantes, ciertos términos seleccionan un subconjunto de objetos dentro de su extensión semántica. Por ejemplo, consideremos las siguientes oraciones: "A Oto le dolió mucho separarse de Ana" y "A Rodolfo le dolió mucho romperse el tobillo". La primera oración selecciona un tipo de dolor emocional distinto al físico que selecciona la segunda, ambos dentro de la extensión del 
término dolor. Ahora imaginemos la siguiente oración dicha por un futbolista que por una lesión se perdió la final de la copa del mundo: "me dolió mucho lastimarme". Parece que la única manera en la que podríamos desambiguar lo que el futbolista ha dicho consiste en entender sus intenciones comunicativas. Si esto es cierto, el textualista habría aceptado que el contenido expresado (al menos para estos casos) está determinado por las intenciones de los hablantes y no por lo que un escucha racional habría entendido. Una vez más, los compromisos acerca del lenguaje y la comunicación adoptados por el textualista juegan en contra de su explicación acerca de la interpretación judicial.

La argumentación de Marmor parece convincente. Sin embargo, es importante señalar que, una vez más, descansa aparentemente en una premisa empírica para la que no ofrece evidencia alguna. ¿Es cierto que los casos de indeterminación que van más allá del contenido asertivo de una prescripción legal son más comunes que los casos en los que dicho contenido no es del todo claro? Por más plausible que parezca una respuesta afirmativa a esta cuestión, existe siempre la posibilidad de que los datos nos muestren lo contrario. Por otro lado, un textualista podría objetar incluso la noción de interpretación ofrecida por Marmor. La interpretación, diría el textualista, está limitada a los casos de indeterminación del contenido asertivo expresado por una ley, pero estos casos no son exhaustivos con respecto a los casos de indeterminación normativa. En ocasiones, el texto de la ley no es la causa de la indeterminación con relación a la solución de un caso particular, mas cuando esto sucede es un exceso utilizar el término "interpretación". Cuando el lenguaje es claro pero los jueces tienen problemas para encontrar una solución al caso, lo que hacen no es interpretar el derecho, sino algo distinto.

El último capítulo ofrece un análisis del debate entre originalistas y dinamistas en el ámbito de la interpretación constitucional. E1 propósito de Marmor es introducir algunas objeciones acerca de las consideraciones lingüísticas que asumen ambas posturas. En general, la tesis de Marmor es que el debate acerca de la interpretación de textos constitucionales ha sido mal entendido por estas posturas como un debate acerca de la mejor caracterización del lenguaje y comu- 
nicación aplicado a la esfera constitucional, pues lo que en realidad está en juego son nuestras visiones morales y políticas acerca de las razones que justifican los sistemas constitucionales y sus condiciones de legitimidad. En otras palabras, este no es un debate sobre qué caracterización del lenguaje y la comunicación explica mejor la manera en la que los jueces deben interpretar el texto constitucional, sino sobre cuál es la concepción político-moral que mejor explica la razón de ser de las constituciones.

De manera muy general, el originalismo sostiene que las instrucciones contenidas en la constitución deben entenderse como fueron entendidas por las asambleas constituyentes que las promulgaron. El dinamismo propone, por el contrario, que las provisiones constitucionales deben leerse tomando en cuenta la manera en la que eran entendidas en el contexto de su promulgación, pero adaptando su contenido a la forma en la que los conceptos que contienen se piensan en el contexto de su interpretación. El capítulo concentra buena parte de su atención en la distinción entre concepto y concepción, y en el fenómeno del desacuerdo en el derecho. La idea es que mientras los conceptos contenidos en la constitución son en cierto sentido estáticos, sus contenidos (concepciones) pueden alterarse a través del tiempo. Otra forma de entender el debate entre originalistas y dinamistas es como una discusión acerca de las concepciones que deben guiar a los jueces al interpretar la constitución. Según el originalismo, las concepciones que los jueces deben tomar en cuenta son aquellas que daban contenido al concepto objeto de la interpretación, en el momento en el que el texto constitucional fue promulgado. Para los dinamistas en cambio, la constitución debe leerse a la luz de las concepciones contemporáneas. Según Marmor, esto es suficiente para afirmar que la discusión entre ambas posturas tiene lugar exclusivamente con relación al campo de la semántica. Aunque distintas en sus compromisos, ambas teorías ofrecen herramientas que las cortes constitucionales podrían utilizar para resolver algunos problemas constitucionales. Sin embargo, ninguna de estas posturas es útil para lidiar con los casos de indeterminación pragmática, en especial aquellos derivados de la polisemia. Dado que los conceptos que contiene la constitución son polisémicos y las con- 
cepciones que les dan contenido son altamente sensibles al contexto en el que son interpretadas, ninguna de las teorías ofrece una buena explicación de la interpretación constitucional. Marmor cree que para resolver el problema es necesario aceptar que la discusión a la que da lugar la indeterminación lingüística en relación con la interpretación de las provisiones constitucionales solo puede resolverse mediante argumentaciones morales y políticas.

El problema con el argumento de Marmor es que, incluso si la crítica a las posturas originalista y dinamista es correcta, su propuesta positiva no se sigue necesariamente. Incluso si los conceptos contenidos en la constitución son polisémicos y su elucidación escapa a la argumentación lingüística, uno podría pensar que tomar una decisión acerca de la manera correcta de leer la constitución es una cuestión arbitraria. En otras palabras, uno podría afirmar que apelar a la justificación en este contexto excede a nuestras capacidades argumentativas, y que es falso que la justificación de nuestros esfuerzos interpretativos esté dada por la corrección de nuestros argumentos políticos y morales.

Como podemos observar, el libro que Marmor nos presenta es por demás interesante. No parece una exageración decir que abre, además, la puerta a una manera novedosa de pensar algunos de los problemas clásicos que durante tiempo han ocupado a los filósofos del derecho. Incluso si mis observaciones son atinadas y algunos de los argumentos no son del todo exitosos, estos sirven para mostrar el camino a seguir por cualquier esfuerzo explicativo futuro. E1 libro, sin lugar a dudas, se convertirá en poco tiempo en una referencia obligada para quienes buscan explorar la relación entre el derecho y el lenguaje. 


\section{Bibliografía}

Endicott, T., "The Value of Vagueness", en Vagueness in Normative Texts, Vijay K. Bhatia, Jan Engberg, Maurizio Gotti y Dorothee Heller (eds.), Bern: Peter Lang, 2008.

Davis, W., "Implicature", en Edward N. Zalta (ed.), Stanford: Stanford Encyclopedia of Philosophy, n. d.

Marmor, A., The Language of Law, Oxford: Oxford University Press, 2014. 